\title{
The effects of mediator and granular activated carbon addition on degradation of trace organic contaminants by an enzymatic membrane reactor
}

\section{Revised Manuscript Submitted to \\ Bioresource Technology}

May, 2014

Luong N. Nguyen ${ }^{a}$, Faisal I. Hai ${ }^{\mathrm{a}}{ }^{*}$, William E. Price ${ }^{\mathrm{b}}$, Frederic D. L. Leusch ${ }^{\mathrm{c}}$, Felicity Roddick $^{\mathrm{d}}$, Hao H. Ngo ${ }^{\mathrm{e}}$, Wenshan Guo ${ }^{\mathrm{e}}$, Saleh F. Magram ${ }^{\mathrm{f}}$ and Long D. Nghiem ${ }^{\mathrm{a}}$

${ }^{a}$ Strategic Water Infrastructure Lab, School of Civil, Mining and Environmental Engineering, University of Wollongong, Wollongong, NSW 2522, Australia

${ }^{\mathrm{b}}$ Strategic Water Infrastructure Lab, School of Chemistry, University of Wollongong, Wollongong, NSW 2522, Australia

${ }^{c}$ Smart Water Research Centre, Griffith University, QLD 4222, Australia

${ }^{\mathrm{d}}$ School of Civil, Environmental and Chemical Engineering, RMIT University, Melbourne, Victoria 3001, Australia

${ }^{\mathrm{e}}$ Centre for Technology in Water and Wastewater, School of Civil and Environmental Engineering, University of Technology Sydney, Sydney, Broadway, NSW 2007, Australia ${ }^{\mathrm{f}}$ Department of Civil Engineering, King Abdul Aziz University, Jeddah 21589, Saudi Arabia

*Corresponding author: Faisal I. Hai, E-mail: faisal@uow.edu.au, Ph: + 61242213054 


\begin{abstract}
The removal of four recalcitrant trace organic contaminants (TrOCs), namely carbamazepine, diclofenac, sulfamethoxazole and atrazine by laccase in an enzymatic membrane reactor (EMR) was studied. Laccases are not effective for degrading non-phenolic compounds; nevertheless, 22-55\% removal of these four TrOCs was achieved by the laccase EMR. The addition of the redox-mediator syringaldehyde (SA) to the EMR resulted in a notable dosedependent improvement (15-45\%) of TrOC removal affected by inherent TrOC properties and loading rates. However, SA addition resulted in a concomitant increase in the toxicity of the treated effluent. A further 14-25\% improvement in aqueous phase removal of the TrOCs was consistently observed following a one-off dosing of $3 \mathrm{~g} / \mathrm{L}$ granular activated carbon (GAC). Mass balance analysis reveals that this improvement was not due solely to adsorption but also enhanced biodegradation. GAC addition also reduced membrane fouling and the SA-induced toxicity of the effluent.
\end{abstract}

Keywords: Enzymatic membrane reactor (EMR); granular activated carbon (GAC); laccase; redox-mediator; syringaldehyde; trace organic contaminants (TrOCs). 


\section{Introduction}

Enzymatic transformation of organic contaminants that are otherwise resistant to conventional activated sludge treatment is a promising eco-friendly concept (Jochems et al., 2011). Enzymatic treatment can be accomplished under mild conditions, achieves high reaction specificity and rates, and generally only requires a small dosage. However, the application of enzymatic treatment in a continuous system remains a challenge due to enzyme washout with the treated effluent (Hai et al., 2012). The use of membranes with pore size smaller than the enzyme molecule presents an elegant approach to preventing enzyme wash out (Lloret et al., 2012). In an enzymatic membrane reactor (EMR), the enzyme remains within the reactor allowing operation with continuous feeding and treated effluent withdrawal. Compared to the conventional approach of enzyme immobilization on a suitable support material (Cabana et al., 2009), the EMR system offers several advantages such as more effective retention of enzymes, dispersion of enzymes in the reactor (eliminating the mass transfer limitations typically associated with attachment on supports), and easy replenishment of fresh enzymes during long term operation.

Recent studies have explored EMRs for the treatment of pollutants such as dyes and aromatic hydrocarbons (Chhabra et al., 2009; Mendoza et al., 2011). Trace organic contaminants (TrOCs) is a group of emerging pollutants that have been routinely detected in sewage and sewage-impacted natural water at concentrations ranging from $\mathrm{ng} / \mathrm{L}$ to $\mu \mathrm{g} / \mathrm{L}$ (Boonyaroj et al., 2012; Navaratna et al., 2012). TrOCs can be classified into several groups including pharmaceuticals and personal care products, pesticides, steroid hormones, phytoestrogens, and industrial chemicals. Many of these TrOCs can cause adverse physiological changes in aquatic organisms and can potentially affect human health after prolonged exposure. To date, 
the enzymatic removal of TrOCs has been mostly investigated in batch tests (Tran et al., 2010; Yang et al., 2013a) using different enzymes such as laccase, lignin peroxidase, and manganese peroxidase. Among these enzymes, laccase (Benzenediol: oxygen oxidoreductase; EC 1.10.3.2) is of particular interest as it only requires molecular oxygen as a co-substrate. Recent studies have demonstrated that laccase can effectively degrade a range of TrOCs that are otherwise resistant to conventional biological processes (Marco-Urrea et al., 2009; Tran et al., 2010; Yang et al., 2013a). TrOC removal by an enzymatic system is dependent on various factors including the molecular structure of the TrOCs, $\mathrm{pH}$, temperature, and properties of the specific enzyme. To date, only one study has investigated continuous TrOC degradation by EMR (Lloret et al., 2012). Effective removal of two phenolic compounds (which are known as good substrates for laccase), namely estrone and $17 \beta$-estradiol, was demonstrated albeit over a limited observation period of $8 \mathrm{~h}$.

Phenolic substrates are particularly amenable to degradation by laccase. The substrate range of laccase can be expanded in the presence of small molecular weight redox-mediators that act as an 'electron shuttle' between the enzyme and the target compounds. The degree of enhancement depends predominantly on the type of mediator and TrOC structure (Yang et al., 2013a). However, TrOC degradation by the mediator-enhanced laccase system has been studied almost exclusively in batch tests. There is only one study utilising the addition of both laccase and hydroxybenzotriazole (HBT) every $8 \mathrm{~h}$ and achieving a carbamazepine removal of $60 \%$ within $24 \mathrm{~h}$, compared to about $20 \%$ removal with a single addition of laccase and HBT (Hata et al., 2010). In this context, continuous dosing of a mediator to EMR may achieve an enhanced removal of TrOCs. However, no work in this line could be identified in the literature.

Adsorption onto powdered activated carbon (PAC) or granular activated carbon (GAC) can efficiently remove TrOCs from water. However, limited adsorption of ionic compounds, 
particularly of those containing electron-withdrawing functional groups, has been reported. In this connection, the concept of combined processes such as coupling of membrane bioreactors with PAC/GAC has been explored in a few recent studies (Li et al., 2011; Nguyen et al., 2013a). Available data confirms short-term enhancement in removal of resistant TrOCs but highlights the requirement of periodic withdrawal and replenishment of activated carbon. Because laccase can degrade TrOCs that are inefficiently degraded by conventional biological processes, activated carbon dosing to an EMR may lead to enhanced biodegradation rather than only temporary improvement in aqueous phase removal. However, no previous attempts have been made to validate this hypothesis.

This study aims to investigate the removal of four selected TrOCs, known to be resistant to conventional activated sludge treatment, by an EMR using laccase. The two hypotheses noted above to enhance the degradation of TrOCs, namely (i) continuous addition of a redoxmediator, and (ii) simultaneous addition of a redox mediator and GAC, have been systematically validated. Implications of GAC addition on TrOC removal, membrane fouling and the toxicity of the treated effluent are also discussed.

\section{Materials and methods}

\subsection{Trace organic contaminants}

Three pharmaceutically active compounds, namely carbamazepine (CBZ), diclofenac (DCF), and sulfamethoxazole (SMX) and the pesticide atrazine (ATZ) were selected based on their widespread occurrence in raw sewage and sewage-impacted water bodies as well as their resistance to conventional biological treatment processes. These are non-phenolic compounds with molecular weights ranging from 215 (ATZ) to 296 (DCF) Da and with $\log \mathrm{D}_{(\mathrm{pH}=6)}$ (indicating hydrophobicity) ranging from 0.43 (SMX) to 2.72 (DCF) (Supplementary Data Table S1). Analytical grade (>98\%) standards of these TrOCs were purchased from Sigma- 
Aldrich (Castle Hill, NSW, Australia). A stock solution containing $1 \mathrm{~g} / \mathrm{L}$ of each compound was prepared in pure methanol. This stock solution was stored at $-18{ }^{\circ} \mathrm{C}$ in the dark and was used within one month.

\subsection{Enzyme solution, mediator and granular activated carbon}

A commercially available laccase (Novozym 51003) purified from genetically modified Aspergillus oryzae was supplied by Novozymes Australia Pty Ltd. This enzyme has a molecular weight of $56 \mathrm{kDa}$. The enzyme stock solution had a density, purity and activity of $1.12 \mathrm{~g} / \mathrm{mL}$, approximately $10 \%(\mathrm{w} / \mathrm{w}$ ) and 150,000 $\mu \mathrm{M} / \mathrm{min}$ (measured using 2,6-dimethoxy phenol (DMP) as substrate), respectively.

The radicals generated due to oxidation of syringaldehyde (SA) by laccase have been reported to be more stable than those of other common redox-mediators (e.g. HBT) (González Arzola et al., 2009). Therefore, SA obtained from Sigma-Aldrich (NSW, Australia) was used in this study as the redox- mediator. A stock solution of SA was prepared in Milli-Q water at a concentration of $50 \mathrm{mM}$ and stored at $4{ }^{\circ} \mathrm{C}$.

GAC-1200 (Activated Carbon Technologies Pty Ltd, Victoria, Australia) was chosen as adsorbent because of its high TrOC adsorption capacity (Nguyen et al., 2013a). The physicochemical characteristics of this GAC are summarized in Supplementary Data Table S2. Prior to the experiment, the GAC was washed with Milli-Q water to remove fine particles, dried at $105{ }^{\circ} \mathrm{C}$ for $24 \mathrm{~h}$ and stored at room temperature until use.

\subsection{Batch test description}

The impact of GAC and/or SA addition on enzymatic degradation of TrOCs was first investigated in batch tests. Parallel tests on different combinations (i.e., enzyme only, GAC only, enzyme + GAC, enzyme + SA, and enzyme + GAC + SA) were conducted with 200 $\mathrm{mL}$ test media in $400 \mathrm{~mL}$ beakers. In all tests, each TrOC was added at an initial nominal 
concentration of $5000 \mu \mathrm{g} / \mathrm{L}$ (actual concentrations of $5600 \pm 110,4900 \pm 160,4700 \pm 100$, and $4300 \pm 400 \mu \mathrm{g} / \mathrm{L}$ for CBZ, DCF, SMX and ATZ, respectively). The initial enzymatic activity of the test solution was $90 \mu \mathrm{M} / \mathrm{min}$. The enzymatic activity was selected based on a preliminary experiment (data not shown) showing that the enzymatic activity in the range of 60 to $90 \mu \mathrm{M} / \mathrm{min}$ resulted in approximately $80 \%$ removal of DCF at an initial concentration of $1000 \mu \mathrm{g} / \mathrm{L}$. The enzymatic assay has been described in Section 2.5.2. SA was added at a concentration of $10 \mu \mathrm{M}$ and a GAC dosage of $20 \mathrm{mg} / \mathrm{L}$ was used. The initial concentrations of the TrOCs and GAC were selected such that the TrOC loading exceeded the maximum adsorption capacity of the GAC ( 250 and $94.3 \mathrm{mg} / \mathrm{g} \mathrm{GAC}$ for CBZ and DCF, respectively (Nguyen et al., 2013a)) allowing the effect of enzyme and mediators to be clearly observed. Triplicate samples were collected after $24 \mathrm{~h}$ of incubation to measure TrOC removal from the aqueous phase. The samples were diluted two-fold in methanol to immediately stop any residual enzyme activity. TrOC adsorbed on GAC was measured by a solvent extraction method (Wijekoon et al., 2013). Freeze-dried GAC was thoroughly mixed with $5 \mathrm{~mL}$ of methanol. The mixture was then sonicated for $10 \mathrm{~min}$ and the supernatant was collected. The remaining solid mass was subjected to further extraction using $5 \mathrm{~mL}$ methanol and dichloromethane $(1: 1 \mathrm{v} / \mathrm{v})$ and the supernatant was collected. The extracted TrOC in the solution was measured by HPLC analysis as described in Section 2.5.1. The extraction efficiency of CBZ, DCF, SMX and ATZ from GAC was 64, 98, 82 and 79\%, respectively.

\subsection{Enzymatic membrane reactor system and operation protocol}

A laboratory scale EMR system consisting of a $1.5 \mathrm{~L}$ (active volume) glass reactor was used (Supplementary Data Figure S3). An ultrafiltration hollow fibre membrane made of polyacrylonitrile (Pall Corporation, NSW, Australia) was submerged in the reactor. The membrane had a nominal molecular weight cut off (MWCO), surface area and clean water flux of $6 \mathrm{kDa}, 0.19 \mathrm{~m}^{2}$, and $10 \mathrm{~L} / \mathrm{h}$. bar, respectively. 


\subsubsection{Confirmation of enzyme retention by the membrane}

Stock solution $(1 \mathrm{~mL})$ of laccase was diluted to a final volume of $1.5 \mathrm{~L}$ in the reactor by Milli-Q water to obtain an initial enzymatic activity of approximately $90 \mu \mathrm{M} / \mathrm{min}$. The membrane was operated at a flux of $1.1 \mathrm{~L} / \mathrm{m}^{2} . \mathrm{h}$ via a peristaltic pump (Masterflex L/S, USA) for $24 \mathrm{~h}$ at $8 \mathrm{~min}$ on and $1 \mathrm{~min}$ off cycles, and the permeate was returned to the reactor. Enzymatic activity in permeate and reactor supernatant samples was measured every $30 \mathrm{~min}$ in the first $4 \mathrm{~h}$, and then every $5 \mathrm{~h}$ until $24 \mathrm{~h}$. The reactor was placed in a water bath with a temperature control unit (Julabo, Germany) to maintain the temperature at $28{ }^{\circ} \mathrm{C}$. Dissolved oxygen (DO) concentration was maintained at above $3 \mathrm{mg} / \mathrm{L}$ via an air pump (ACO-002, Zhejiang Sensen Industry Co. Ltd, Zhejiang, China) connected to a diffuser placed at the bottom of the reactor. The $\mathrm{pH}$ of the reactor was $6.8 \pm 0.2$. Transmembrane pressure (TMP) was continuously monitored using a high-resolution $( \pm 0.1 \mathrm{kPa})$ pressure sensor (SPER scientific 840064, Extech Equipment Pty Ltd, Victoria, Australia) connected to a computer for data logging.

\subsubsection{Stability of enzymatic activity}

In order to check the stability of enzymatic activity under the applied hydraulic conditions and continuous TrOC dosing $(1660 \mu \mathrm{g} / \mathrm{L} . \mathrm{d})$, the EMR was operated at a hydraulic retention time (HRT) of $8 \mathrm{~h}$ with continuous permeate withdrawal. All other conditions were as described in Section 2.4.1. Operation was initiated with an enzymatic activity of $90 \mu \mathrm{M} / \mathrm{min}$. Permeate samples from the membrane and supernatant samples from the reactor were taken every $5 \mathrm{~h}$ for determining TrOC removal and enzymatic activity until no enzymatic activity was detected in the reactor $(72 \mathrm{~h})$. Then, another dose of enzyme was added to the EMR to reinstate the enzymatic activity to the initial level $(90 \mu \mathrm{M} / \mathrm{min})$, and the above run was repeated. 


\subsubsection{Continuous operation of the EMR}

The EMR was continuously operated for $66 \mathrm{~d}$ to investigate TrOC degradation by laccase alone or laccase in the presence of GAC and/or SA. Based on the observed enzymatic stability (Section 2.4.2), laccase was injected (200 $\mu \mathrm{L}$ laccase/ L reactor volume) every $12 \mathrm{~h}$ to the EMR to maintain the enzymatic activity within a range of 70 to $100 \mu \mathrm{M} / \mathrm{min}$. The whole experimental sequence has been detailed in Supplementary Data Table S4. Under each operation regime, the EMR was run for at least a period of $6 \times$ HRT up to $45 \times$ HRT, and samples for measuring TrOC concentration were collected at $2 \times$ HRT following the operation condition change.

The effect of SA addition at different concentrations (i.e., 5, 10 and $20 \mu \mathrm{M}$ ) was investigated under two nominal TrOC loadings (1600 and $830 \mu \mathrm{g} / \mathrm{L} . \mathrm{d})$. Mediator concentrations were selected based on the concentration range used in previous EMR studies targeting recalcitrant compounds such as dyes (Chhabra et al., 2009; Mendoza et al., 2011) . A single dose of GAC was added to the EMR on Day 30 to obtain a final GAC concentration of $3 \mathrm{~g} / \mathrm{L}$. The effect of $\mathrm{GAC}$ addition was assessed for $35 \mathrm{~d}$.

\subsubsection{Membrane cleaning protocol}

The UF membrane was cleaned by in-situ Milli-Q water backwash at a flux of $24 \mathrm{~L} / \mathrm{m}^{2} . \mathrm{h}(5$ seconds) when the TMP exceeded $40 \mathrm{kPa}$ during any particular run. Additionally, the membrane was cleaned by ex-situ backwash with 1 L of Milli-Q water followed by 1 L of $\mathrm{NaOCl}\left(500 \mathrm{mg} / \mathrm{L}\right.$ active chlorine) under a flux of $5 \mathrm{~L} / \mathrm{m}^{2} . \mathrm{h}$ at the end of each run. To monitor the formation of an enzyme gel layer on the membrane surface, the enzymatic activity of the cleaning solution was measured after each ex-situ Milli-Q water backwash.

\subsection{Analytical methods}

\subsubsection{TrOC analysis}


A HPLC system (Shimadzu, Kyoto, Japan), equipped with a $300 \times 4.6 \mathrm{~mm}(5 \mu \mathrm{m}$ pore size) C-18 column (Supelco Drug Discovery, Sigma-Aldrich, Australia) and an UV-vis detector, was used to measure TrOC concentrations. The detection wavelength, column temperature, and sample injection volume were $280 \mathrm{~nm}, 20^{\circ} \mathrm{C}$, and $50 \mu \mathrm{L}$, respectively. The mobile phase comprised of acetonitrile and Milli-Q water buffered with $25 \mathrm{mM} \mathrm{KH}_{2} \mathrm{PO}_{4}$. Two eluents, $\mathrm{A}$ ( $80 \%$ acetonitrile and $20 \%$ buffer, v/v) and B (20\% acetonitrile and $80 \%$ buffer, v/v) were delivered at $0.7 \mathrm{~mL} / \mathrm{min}$ through the column for $30 \mathrm{~min}$ in a time-dependent gradient proportions [Time (min), B (\%)]: [0, 85], [5, 40], [8, 0], [22, 85] (Hai et al., 2011). The limit of quantification for the analytes under investigation using these conditions was approximately $10 \mu \mathrm{g} / \mathrm{L}$. The removal efficiency was calculated as $R=100 \times\left(1-\frac{C_{E f f}}{C_{I n f}}\right)$, where $\mathrm{C}_{\mathrm{Inf}}$ and $\mathrm{C}_{\mathrm{Eff}}$ are influent and effluent (permeate) concentrations of the TrOC, respectively.

\subsubsection{Enzymatic and toxicity assay}

Laccase activity was determined by monitoring the oxidation of $10 \mathrm{mM}$ DMP in $100 \mathrm{mM}$ sodium citrate buffer solution ( $\mathrm{pH} 4.5$ ) over $2 \mathrm{~min}$ at room temperature. The measurement was based on the change in colour and measured at $\lambda=468 \mathrm{~nm}$ by a spectrophotometer (UVVisible UV-1700, Shimadzu, Kyoto, Japan). Laccase activity was calculated from the molar extinction coefficient $\varepsilon=49.6 / \mathrm{mM} . \mathrm{cm}$ and expressed in $\mu \mathrm{M} / \mathrm{min}$ (Hai et al., 2012).

The bacterial toxicity of feed and permeate was analysed in duplicate by measuring bioluminescence inhibition in Photobacterium leiognathi (ToxScreen3 assay; CheckLight

Ltd, Israel) as described previously (Nguyen et al., 2013b). Toxicity was expressed as relative Toxic Unit (rTU), calculated as $\mathrm{rTU}=1 / \mathrm{IC}_{20}$, with $\mathrm{IC}_{20}$ (concentration of the sample required to kill $20 \%$ of the bacteria) determined by linear regression of the toxicity response $v s$. relative sample enrichment within the linear range of the concentration-effect curve (up to $\mathrm{IC} 40)$. 


\section{Results and discussion}

\subsection{Batch tests: assessment of treatment capacity of each option studied}

Although phenols are typical laccase substrates, laccase can directly oxidize some nonphenolic compounds if the electrochemical potential of the laccase used is sufficiently high (González Arzola et al., 2009). However, the laccase preparation used in this study did not efficiently degrade the tested non-phenolics (Table 1), with the highest removal of $21 \%$ being achieved for DCF. Similarly, even after SA addition, except for DCF (64\%) all compound removals ranged between 16 and $31 \%$. The recalcitrance of the selected TrOCs in this study can be attributed to their chemical structures. According to Tadkaew et al. (2011) the presence of electron withdrawing groups $(\mathrm{EWG})$ in TrOCs imparts resistance to oxidative catabolism. Therefore the low removal of CBZ can be attributed to the presence of strong EWG amide in its structure (Yang et al., 2013a). The low removal of the chlorinated TrOCs DCF and ATZ can similarly be explained by the fact that chloride is a strong EWG. This is consistent with a report by Tran et al. (2010) who also observed the resistance of chlorinated TrOCs to laccase treatment. Resistance of ATZ is also consistent with previous reports on inherent resistance of triazine pesticides (Navaratna et al., 2012). Among the sulfonamide antibiotics, thus far, only limited information on the enzymatic degradation of SMX is available. Consistent with this study, Yang et al. (2013b) reported negligible removal of SMX by a crude extracellular extract preparation (mainly laccase) from Trametes versicolor.

\section{[TABLE 1]}

Only DCF degradation was significantly improved by SA addition (Table 1). This may be due to the presence of the aromatic amine group (an electron donating group, EDG) in its structure, which possibly lowers its redox potential and makes it amenable to oxidation by laccase preparation when amended with SA. However, it could not be clarified why despite having an amine group, SMX removal efficiency improved by only $8 \%$ compared to $43 \%$ for 
DCF. This observation, however, is consistent with reports from other studies investigating the electrochemical behavior of DCF (Blanco-Lopez et al., 2005) and SMX (Msagati \& Ngila, 2002) at carbon electrodes: DCF appears to be electrochemically irreversibly oxidized at lower electric potential than SMX. It is also interesting to note that unlike in this study, Weng et al. (2012) observed significant improvement in the removal of sulfadimethoxine and sulfmanomethoxine, which have a similar backbone structure to SMX. This may be explained by the fact that the oxidation reduction potential of the SA-amended laccase solution in this study $(540 \mathrm{mV})$ was lower than that in the study $(626 \mathrm{mV})$ by Weng et al. (2012).

When only GAC was added to the test solution, 49-60\% TrOC removal from the aqueous phase was achieved (Table 1). Therefore, it was not a surprise that the aqueous phase removal ranged from $64-76 \%$ with the simultaneous addition of laccase, SA and GAC. However, it is interesting to note that this improvement in aqueous phase removal (compared with that achieved by the laccase-SA system) was not only due to adsorption on GAC, but also due to enhanced enzymatic degradation. The fate of TrOCs (i.e., residual amount in liquid phase, adsorbed onto GAC and biodegraded) was assessed by extracting residual TrOC from the GAC at the end of the incubation period. The adsorbed amount onto GAC was calculated taking the extraction efficiency into account. It was revealed that a $12-45 \%$ increase in the extent of enzymatic degradation occurred in presence of GAC (Figure 1). Apparently coadsorption of enzyme and TrOC onto GAC facilitated enhanced TrOC degradation. Zille et al. (2003) observed that compared to dye adsorption on alumina, immobilization of enzyme on alumina led to a more consistent dye removal performance due to combined adsorption and biodegradation. Enhanced enzymatic degradation could be further advantageous in a continuous process wherein TrOCs are constantly loaded to the system.

[FIGURE 1] 


\subsection{Performance of EMR}

\subsubsection{Maintenance of enzymatic activity during EMR operation}

Given the molecular weight of the enzyme $(56 \mathrm{kDa})$, it was expected to be retained by the membrane with a MWCO of $6 \mathrm{kDa}$ used in this study. Indeed during continuous filtration over a period of $24 \mathrm{~h}$ (Section 2.4) no enzymatic activity in the permeate was observed, while that in the reactor supernatant remained stable (Supplementary Data Figure S5). Thus it was confirmed that the membrane effectively retained the enzyme.

In addition to enzyme retention, the maintenance of enzyme activity during EMR operation is an important factor. Denaturation of enzyme due to various factors including physical, chemical and biological inhibitors and the effect of shear stress during filtration has been reported in the literature. The situation may be further exacerbated when a wastewater containing the target pollutant is continuously introduced to the reactor (Mendoza et al., 2011). There is only one study on continuous TrOC (estrone and estradiol) degradation by an EMR (Lloret et al., 2012), where no enzyme denaturation within the short observation period of $8 \mathrm{~h}$ was observed. In this study, however, a gradual drop in the enzymatic activity within the reactor was noted beyond $24 \mathrm{~h}$ of continuous operation (data not shown), although the enzyme was still undetectable in the permeate, indicating that the observed decrease in enzymatic activity was due to enzyme denaturation rather than the permeation of enzyme through the membrane. To sustain continuous operation, a low dose laccase injection protocol was developed following several trials: the enzymatic activity was maintained at 70-100 $\mu \mathrm{M} / \mathrm{min}$ by addition of $200 \mu \mathrm{L}$ of the commercial laccase solution per $\mathrm{L}$ of the reactor volume every $12 \mathrm{~h}$ (equivalent to a laccase dose of $23 \mathrm{mg} / \mathrm{L} . \mathrm{d}$ ).

\subsubsection{Continuous removal of TrOC by EMR}


The removal efficiency of the compounds by the EMR followed the same order as in batch tests, i.e., DCF $>$ ATZ $>$ CBZ $>$ SMX. Although a direct comparison of removal efficiency between two operation modes (i.e., batch $v s$. continuous) may not be valid, it is notable that the removal efficiency of DCF by the EMR was around 60\% (Figure 2), which was three times that achieved during batch tests. The removal of the other compounds by EMR was slightly higher as well. The improved removal by the EMR despite continuous dosing of TrOCs can be attributed to the fact that in order to assess the contribution of adsorption and biodegradation, the batch tests (Section 2.3) were conducted under an initial TrOC concentration $(5000 \mu \mathrm{g} / \mathrm{L}) 10$ times that fed to the EMR. The effect of TrOC loading on the performance of the EMR was directly evidenced by a compound-specific improvement (3 to $12 \%$ ) in removal efficiency when the TrOC loading was reduced to approximately half from $1660 \mu \mathrm{g} / \mathrm{L} . \mathrm{d}$ (Figure 2 and Supplementary Data Table S6). The removal of these nonphenolic TrOCs by EMR has not been reported before. However, the effect of TrOC loading was also demonstrated in a study by Lloret et al. (2012), who reported that the removal of estrone (a phenolic TrOC) increased from 64 to $73 \%$ when the loading decreased from 4 $\mathrm{mg} / \mathrm{L} . \mathrm{h}$ to $1 \mathrm{mg} / \mathrm{L} . \mathrm{h}$.

[FIGURE 2]

\subsection{Impact of mediator addition on EMR performance}

In a laccase-mediator system, the role of laccase is to oxidize the mediator, while the actual oxidation of the substrate takes place in a subsequent non-enzymatic step by the action of the oxidized mediator species. The oxidation of SA by laccase generates highly active phenoxyl $\left(\mathrm{C}_{6} \mathrm{H}_{5} \mathrm{O}^{*}\right)$ radicals, which then target substrate via a hydrogen atom transfer (HAT) route (Fabbrini et al., 2002). This HAT mechanism has been implicated for the oxidation of 
resistant species such as non-phenolic compounds. However, to date the use of mediators to improve TrOC removal has been reported in mostly batch test studies (Yang et al., 2013a).

In this study the addition of SA to EMR resulted in significant improvement in TrOC removal depending on the mediator dose as well as the TrOC type and loading (Figure 2 and Supplementary Data Table S6). Two notable observations were made: (i) achievement of significant improvements in removal up to a mediator dose of $10 \mu \mathrm{M}$, and (ii) the impact of TrOC loading on the removal performance by the laccase-SA system.

No continuous flow EMR study on TrOC removal could be found in the literature to compare our data to. There is one batch study which was conducted with repeated addition of laccase and a mediator (HBT) every $8 \mathrm{~h}$ for CBZ removal over a period of $48 \mathrm{~h}$ (Hata et al., 2010). Following this strategy, the authors reported an elimination of $60 \%$, which compared favourably with a removal of $20 \%$ achieved via a single dose of HBT. In general, the better performance of the laccase-SA system may be explained by two factors attributable to the radical species generated from SA by laccase: i) higher redox potential, and ii) reduction of steric hindrance. Low molecular weight mediators can interact with complex compounds that cannot access the active sites of the enzyme directly. Moreover, compounds with high electrochemical potential can be oxidized by radical mediators (i.e., phenoxyl) through the operation of H-abstraction mechanism.

Our results are in line with the general trend observed in the literature that pollutant removal profile may reach a plateau beyond a certain mediator concentration (10 $\mu \mathrm{M}$ in this study) (Mizuno et al., 2009). This occurs because the free radicals generated from laccasemediator systems that can improve pollutant degradation may also inactivate laccase by oxidizing the aromatic amino acid residues on the proteinaceous enzyme surface (KhlifiSlama et al., 2012). Another notable observation in this study was the impact of TrOC 
loading on the performance of the laccase-SA system. During EMR operation, the effect of TrOC loading was particularly significant for ATZ (Figure 2). Furthermore, compared with batch tests, which were conducted under higher (10 times) TrOC concentrations (Table 1), better performance during EMR operation with the same SA dose $(10 \mu \mathrm{M})$ was observed for all tested TrOCs except DCF, which was well removed in both cases. This observation once again illustrates the significant impact of TrOC loading on enzymatic removal of the resistant TrOCs. At high substrate concentrations, when almost all of the enzyme molecules are bound to the substrate, the reaction rate is dependent solely on the amount of enzyme and, therefore, occurs with zero-order kinetics.

In this study, continuous dosing of the mediator was required because it was not retained by the membrane utilized. It is noted that continuous dosing of mediators to EMR is not ideal and may hinder its wides-spread applicability due to mediator cost and more complex operation. In this context, immobilization of the mediator or its recovery from the treated effluent may be applied. For example, Mendoza et al. (2011) confirmed that a membrane with a MWCO of $10 \mathrm{kDa}$ could retain the mediator TEMPO which was immobilized on polyethylene glycol. The EMR achieved efficient treatment of a dye wastewater for nine repeated batches with a single addition of the mediator. In another study by Chhabra et al. (2009), a recovery of $70 \%$ of ABTS was achieved from the treated effluent using ammonium sulphate precipitation method. It would be interesting to observe TrOC removal with the incorporation of such strategies. However, it is beyond the scope of the current study.

\subsection{Effect of GAC addition on EMR performance}

Following the single dose addition of GAC, the EMR was operated for $35 \mathrm{~d}$ with continuous feeding and periodic injection of laccase. The TrOC loading and SA concentration were 
varied systematically over $830-1660 \mu \mathrm{g} / \mathrm{L} . \mathrm{d}$ and 5-20 $\mu \mathrm{M}$, respectively (Supplementary Data Table S4). A stable and improved removal of all three resistant TrOCs (i.e., CBZ, SMX and ATZ) was observed for SA concentrations of 5 and $10 \mu \mathrm{M}$ (Figure 3 and Supplementary Data Table S6). For example, with a SA dose of $5 \mu \mathrm{M}$ and a TrOC loading of $830 \mu \mathrm{g} / \mathrm{L} . \mathrm{d}$ (each), 14-25\% improvement in removal was observed following GAC addition (Figure 3). Notably, irrespective of TrOC loading and SA dose, the removal of DCF remained around $80 \%$, which was already achieved without GAC addition.

\section{[FIGURE 3]}

Over the period of continuous operation of the EMR following GAC addition, the total mass of TrOCs fed to the reactor did not exceed the maximum adsorption capacity of the GAC added to the EMR. However, data from EMR operation, in line with the batch test data, indicates that the improved and stable aqueous phase removal achieved by the GAC-amended EMR was not only due to adsorption of TrOCs but also due to subsequent enzymatic degradation of the adsorbed amount. At the end of the EMR operation, residual amounts of TrOCs on GAC were measured and a mass balance was conducted which revealed that a major portion of the TrOCs retained within the EMR (as indicated by the difference in TrOC concentration in feed and permeate) was biodegraded (Table 2). Removal of the selected TrOCs in this study by volatilization was expected to be negligible because of the very low vapour pressure or Henrys's constant $(\mathrm{H})$ and low H/log D ratio (Supplementary Data Table S1) of the TrOCs investigated, and photolysis was avoided by covering the EMR. Thus, enzymatic degradation appeared to be the major mechanism of TrOC removal by the GACamended EMR system.

[TABLE 2] 
The results reported here indicate that in a GAC-amended EMR system, simultaneous adsorption of TrOCs and enzyme on GAC can enable enhanced enzymatic degradation of TrOCs bound on GAC, and lead to overall improvement of TrOC degradation, possibly because it promotes the interaction of TrOCs with the active sites of enzyme. Similar phenomena have been observed when activated carbon (GAC or PAC) was added to conventional membrane bioreactors (Li et al., 2011) or fungal reactors (Hai et al., 2008; Zhang \& Yu, 2000). For example, Zhang and Yu (2000) encapsulated PAC inside fungal mycelium pellets and applied them for the removal of dye. It was shown that the PAC facilitated co-adsorption of the dye molecules and the extracellular enzyme secreted by fungal cells and achieved enhanced dye degradation. Co-adsorption of enzyme and dye on PAC and subsequent enzymatic dye degradation was also confirmed in a study by Hai et al. (2008). Moreover, it is possible that the adsorption of enzyme on GAC stabilizes enzymatic activity. This is supported by the observations made in studies involving enzyme immobilization on activated carbon (Jochems et al., 2011). The adsorption of TrOCs on GAC can also enhance degradation by increasing the contact time between the TrOCs and the enzyme.

\subsection{Membrane performance}

\subsubsection{Role of the membrane in TrOC removal}

A significant level of enzymatic activity in the membrane cleaning solution from ex-situ Milli-Q backwashing was observed in this study. The enzymatic activity in $1 \mathrm{~L}$ of the cleaning solution was $60 \mu \mathrm{M} / \mathrm{min}$, which was equivalent to an accumulation of at least $0.24 \mathrm{~g}$ active laccase per $\mathrm{m}^{2}$ of membrane surface. This demonstrated that an enzyme gel layer was formed on the membrane surface. Therefore, the TrOC concentration in permeate and supernatant of the reactor was measured periodically to investigate if there was any additional removal by the membrane and/or enzyme layer on the membrane. The ratio of concentration 
of TrOCs in permeate and supernatant (P/S ratio) was indeed below 1 for all TrOCs (Figure 4). Without addition of SA or GAC, the lowest P/S ratio was observed in case of DCF $(0.52 \pm 0.02, \mathrm{n}=11)$. Interestingly, the $\mathrm{P} / \mathrm{S}$ ratio of DCF did not change significantly following addition of SA or GAC, which is consistent with its high removal by laccase alone (Figure 2). Conversely, for a TrOC loading of $830 \mu \mathrm{g} / \mathrm{L} . \mathrm{d}$, the P/S ratios of CBZ and ATZ dropped significantly following GAC addition. It is noted that GAC particles did not significantly accumulate on the membrane surface, but rather remained mainly in suspension by aeration within the reactor. However, the drop in $\mathrm{P} / \mathrm{S}$ ratio indicates that adsorption on the suspended GAC facilitated retention of TrOCs within the reactor.

No EMR study could be found to directly compare these results, but the observations made in this study are in line with that by Li et al. (2011) who reported significant additional removal of CBZ and SMX by a microfiltration membrane submerged in a conventional activated sludge bioreactor to which PAC was added. A stable TrOC removal was achieved throughout this study, and there was no accumulation of TrOCs within the EMR (as evidenced by a stable concentration in the reactor supernatant). It can therefore be said that TrOCs adsorbed on the enzyme gel layer over the membrane were subsequently degraded. Dosing of GAC to an EMR can realize advantages additional to improved TrOC degradation, and these aspects have been discussed in Sections 3.5.2 and 3.6.

\section{[FIGURE 4]}

\subsubsection{Membrane fouling}

Membrane fouling is an important aspect that requires due consideration when operating a continuous flow EMR. The formation of an enzyme gel layer on the membrane (Section 3.5.1) can lead to its gradual fouling (Jochems et al., 2011). In this study, during EMR 
operation without GAC, a TMP build up rate of approximately $9 \mathrm{kPa} / \mathrm{d}$ was observed (Figure 5). By contrast, following GAC addition, an initial TMP build up rate of approximately 3.3 $\mathrm{kPa} / \mathrm{d}$ was noted, which further dropped to $2.5 \mathrm{kPa} / \mathrm{d}$ within a month of operation after the single dose addition of GAC.

The data reported here suggests that a dynamic layer of adsorbent over the membrane can be beneficial for long-term restoration of the membrane permeability. It is also likely that the scouring action of the GAC particles helped to restrict the overgrowth of the enzyme gel layer on the membrane surface, thus reducing the overall hydrodynamic boundary layer thickness on the membrane compared with operation without GAC. Previous studies have demonstrated that the addition of adsorbents such as activated carbon (PAC or GAC) can mitigate membrane fouling in membrane bioreactors ( $\mathrm{Ng}$ et al., 2013). This study, however, is possibly the first to demonstrate the advantage of GAC dosing for mitigation of membrane fouling in an EMR.

\section{[FIGURE 5]}

\subsection{Toxicity of treated effluent}

A few recent batch test studies have shown increased toxicity of enzyme-treated media despite efficient degradation of the target pollutant (Marco-Urrea et al., 2009). In this study, a ToxScreen3 assay (Section 2.5.2) revealed no significant toxicity in the feed irrespective of the feed concentration $(6.6 \pm 0.3 \mathrm{rTU} ; \mathrm{n}=4)$ indicating that the tested TrOCs were not particularly toxic to the indicator bacterium (P. leiognathi) used in this study (Supplementary Data Figure S7). There was also no appreciable increase in toxicity in the EMR permeate (7.0 $\pm 1.7 \mathrm{rTU} ; \mathrm{n}=2$ ), suggesting that treatment did not produce toxic by-products. On the other 
hand, addition of the redox-mediator SA to the EMR considerably increased the toxicity of the permeate. The toxicity of treated effluent with SA dosage of $5 \mu \mathrm{M}$ and $10 \mu \mathrm{M}$ was $20.1 \pm$ $5(n=2)$ and $41.7 \pm 2.1$ rTU $(n=2)$, respectively. This corresponds to $2.8 \times$ and $6.0 \times$ increase in toxicity, respectively.

The observed toxicity of treated effluent after SA addition is consistent with a report by Fillat et al. (2010) who studied the treatment of flax pulp. The toxicity of the treated medium, despite efficient TrOC removal after SA addition, may be due to the phenoxyl radicals formed in the laccase-SA system and/or the metabolites produced during the TrOC degradation. However, the toxicity test for SA itself (incubation with SA solution in the absence of laccase) revealed no toxicity (data not shown). Therefore, the toxicity of the media after enzymatic treatment with or without SA and the negligible toxicity of SA itself indicates that the effluent toxicity is most likely due to the radicals formed in the presence of both laccase and SA. This observation is in accordance with that by Kim and Nicell (2006) who suggested that radicals formed due to oxidation of mediators can interact with vitally important biomolecules and result in cytotoxic effects.

Nevertheless, bacterial assay can only provide a limited measure of ecotoxicity, and while the toxicity results clearly indicate that the effluents are toxic to bacteria, further tests using other organisms are needed to more thoroughly appreciate the potential ecological risks. Moreover, further work is required to screen mediators which enhance enzymatic degradation without raising the toxicity of the treated media. In this context, it is interesting to note that a significant reduction in effluent toxicity originating from SA dosing was observed after the addition of GAC to the EMR (Figure 6). In fact, following GAC addition, the treated effluent demonstrated no elevated toxicity with a SA dose of $5 \mu \mathrm{M}$. It has been previously reported that the effects of shock loads or toxic concentrations of pollutants/chemical species can be 
buffered as a result of their adsorption onto activated carbon. For example, PAC addition to an MBR treating tannery wastewater was shown to reduce the negative effects of natural and synthetic tannins that impart toxicity (Munz et al., 2007). Systematic demonstration of the problem of effluent toxicity originating from mediator dosing to EMR and proposal of a solution is a unique contribution of the current study.

\section{Conclusion}

This is the first report on the multiple advantages of GAC dosing to an EMR: (i) enhancement of TrOC degradation by a laccase—mediator (syringaldehyde) system, (ii) reduction of mediator-induced effluent toxicity, and (iii) mitigation of fouling by an enzyme gel layer over the membrane. TrOCs adsorbed onto the enzyme layer, and GAC addition further facilitated such TrOC retention on the membrane cake layer; nevertheless, subsequent TrOC degradation was confirmed. At a TrOC loading, mediator concentration and GAC dose of $830 \mu \mathrm{g} / \mathrm{L} . \mathrm{d}, 5 \mu \mathrm{M}$, and $3 \mathrm{~g} / \mathrm{L}$, respectively, removal efficiency ranged from $65 \%$ (sulfamethoxazole) to $80 \%$ (diclofenac).

\section{Acknowledgement}

The Australian Government is thanked for an International Postgraduate Research Scholarship (PhD) award to Luong N. Nguyen (University of Wollongong). Novozymes Pty Ltd (Australia) and Activated Carbon Technologies Pty Ltd (Australia) are thanked for the provision of enzyme solution and activated carbon samples, respectively. Laboratory assistance from Kalinda Watson (Griffith University) for toxicity assay is gratefully acknowledged. 


\section{References}

[1] Blanco-Lopez, M. Carmen, Fernandez-Llano, L., Lobo-Castanon, M.J.-., Miranda-Ordieres, A.J., Tunon-Blanco, P. 2005. Voltammetry of Diclofenac at Graphite, Carbon Composites, and Molecularly Imprinted Polymer-Composite Electrodes. Anal. Lett. 37, 915-927.

[2] Boonyaroj, V., Chiemchaisri, C., Chiemchaisri, W., Theepharaksapan, S., Yamamoto, K. 2012. Toxic organic micro-pollutants removal mechanisms in long-term operated membrane bioreactor treating municipal solid waste leachate. Bioresource Technol. 113, 174-180.

[3] Cabana, H., Jones, J.P., Agathos, S.N. 2009. Utilization of cross-linked laccase aggregates in a perfusion basket reactor for the continuous elimination of endocrine-disrupting chemicals. Biotechnol. Bioeng. 102, 1582-1592.

[4] Chhabra, M., Mishra, S., Sreekrishnan, T.R. 2009. Laccase/mediator assisted degradation of triarylmethane dyes in a continuous membrane reactor. J. Biotechnol. 143, 69-78.

[5] Fabbrini, M., Galli, C., Gentili, P. 2002. Comparing the catalytic efficiency of some mediators of laccase. J. Mol. Catal., B Enzym. 16, 231-240.

[6] Fillat, A., Colom, J.F., Vidal, T. 2010. A new approach to the biobleaching of flax pulp with laccase using natural mediators. Bioresource Technol. 101, 4104-4110.

[7] González Arzola, K., Arévalo, M.C., Falcón, M.A. 2009. Catalytic efficiency of natural and synthetic compounds used as laccase-mediators in oxidising veratryl alcohol and a kraft lignin, estimated by electrochemical analysis. Electrochim. Acta. 54, 2621-2629.

[8] Hai, F.I., Li, X., Price, W.E., Nghiem, L.D. 2011. Removal of carbamazepine and sulfamethoxazole by MBR under anoxic and aerobic conditions. Bioresource Technol. 102, 10386-10390.

[9] Hai, F.I., Yamamoto, K., Nakajima, F., Fukushi, K. 2012. Application of a GAC-coated hollow fiber module to couple enzymatic degradation of dye on membrane to whole cell biodegradation within a membrane bioreactor. J. Membr. Sci. 389, 67-75.

[10] Hai, F.I., Yamamoto, K., Nakajima, F., Fukushi, K. 2008. Removal of structurally different dyes in submerged membrane fungi reactor-Biosorption/PAC-adsorption, membrane retention and biodegradation. J. Membr. Sci. 325, 395-403. 
[11] Hata, T., Shintate, H., Kawai, S., Okamura, H., Nishida, T. 2010. Elimination of carbamazepine by repeated treatment with laccase in the presence of 1-hydroxybenzotriazole. J. Hazard. Mater. 181, 1175-1178.

[12] Jochems, P., Satyawali, Y., Diels, L., Dejonghe, W. 2011. Enzyme immobilization on/in polymeric membranes: status, challenges and perspectives in biocatalytic membrane reactors (BMRs). Green Chem. 13, 1609-1623.

[13] Khlifi-Slama, R., Mechichi, T., Sayadi, S., Dhouib, A. 2012. Effect of natural mediators on the stability of Trametes trogii laccase during the decolourization of textile wastewaters. J. Microbiol. 50, 226-234.

[14] Kim, Y.-J., Nicell, J.A. 2006. Laccase-catalysed oxidation of aqueous triclosan. J Chem Technol Biotechnol. 81, 1344-1352.

[15] Li, X., Hai, F.I., Nghiem, L.D. 2011. Simultaneous activated carbon adsorption within a membrane bioreactor for an enhanced micropollutant removal. Bioresource Technol. 102, 5319-5324.

[16] Lloret, L., Eibes, G., Feijoo, G., Moreira, M.T., Lema, J.M. 2012. Continuous biotransformation of estrogens by laccase in an enzymatic membrane reactor. Chem. Eng. Trans. 27, 31-36.

[17] Marco-Urrea, E., Perez-Trujillo, M., Vicent, T., Caminal, G. 2009. Ability of white-rot fungi to remove selected pharmaceuticals and identification of degradation products of ibuprofen by Trametes versicolor. Chemosphere. 74, 765-72.

[18] Mendoza, L., Jonstrup, M., Hatti-Kaul, R., Mattiasson, B. 2011. Azo dye decolorization by a laccase/mediator system in a membrane reactor: Enzyme and mediator reusability. Enzyme Microb. Technol. 49, 478-484.

[19] Mizuno, H., Hirai, H., Kawai, S., Nishida, T. 2009. Removal of estrogenic activity of isobutylparaben and n-butylparaben by laccase in the presence of 1-hydroxybenzotriazole. Biodegradation. 20, 533-539.

[20] Msagati, T.A.M., Ngila, J.C. 2002. Voltammetric detection of sulfonamides at a poly(3methylthiophene) electrode. Talanta. 58, 605-610. 
[21] Munz, G., Gori, R., Mori, G., Lubello, C. 2007. Powdered activated carbon and membrane bioreactors (MBR PAC) for tannery wastewater treatment: long term effect on biological and filtration process performances. Desalination. 207, 349-360.

[22] Navaratna, D., Elliman, J., Cooper, A., Shu, L., Baskaran, K., Jegatheesan, V. 2012. Impact of herbicide Ametryn on microbial communities in mixed liquor of a membrane bioreactor (MBR). Bioresource Technol. 113, 181-190.

[23] Ng, C.A., Sun, D., Bashir, M.J.K., Wai, S.H., Wong, L.Y., Nisar, H., Wu, B., Fane, A.G. 2013. Optimization of membrane bioreactors by the addition of powdered activated carbon. Bioresource Technol. 138, 38-47.

[24] Nguyen, L.N., Hai, F.I., Kang, J., Price, W.E., Nghiem, L.D. 2013a. Coupling granular activated carbon adsorption with membrane bioreactor treatment for trace organic contaminant removal: Breakthrough behaviour of persistent and hydrophilic compounds. J. Environ. Manage. 119, 173-181.

[25] Nguyen, L.N., Hai, F.I., Yang, S., Kang, J., Leusch, F.D.L., Roddick, F., Price, W.E., Nghiem, L.D. 2013b. Removal of trace organic contaminants by an MBR comprising a mixed culture of bacteria and white-rot fungi. Bioresource Technol. 148, 234-241.

[26] Tadkaew, N., Hai, F.I., McDonald, J.A., Khan, S.J., Nghiem, L.D. 2011. Removal of trace organics by MBR treatment: The role of molecular properties. Water Res. 45, 2439-2451.

[27] Tran, N.H., Urase, T., Kusakabe, O. 2010. Biodegradation characteristics of pharmaceutical substances by whole fungal culture Trametes versicolor and its laccase. J Water Environ Technol. 8, 125-140.

[28] Weng, S.-S., Ku, K.-L., Lai, H.-T. 2012. The implication of mediators for enhancement of laccase oxidation of sulfonamide antibiotics. Bioresource Technol. 113, 259-264.

[29] Wijekoon, K.C., Fujioka, T., McDonald, J.A., Khan, S.J., Hai, F.I., Price, W.E., Nghiem, L.D. 2013. Removal of N-nitrosamines by an aerobic membrane bioreactor. Bioresource Technol. $141,41-45$.

[30] Yang, S., Hai, F.I., Nghiem, L.D., Price, W.E., Roddick, F., Moreira, M.T., Magram, S.F. 2013 a. Understanding the factors controlling the removal of trace organic contaminants by white-rot 
fungi and their lignin modifying enzymes: A critical review. Bioresource Technol. 141, 97108.

[31] Yang, S., Hai, F.I., Nghiem, L.D., Roddick, F., Price, W.E. 2013b. Removal of trace organic contaminants by nitrifying activated sludge and whole-cell and crude enzyme extract of Trametes versicolor. Water Sci. Technol. 67, 1216-1223.

[32] Zhang, F., Yu, J. 2000. Decolourisation of Acid Violet 7 with complex pellets of white rot fungus and activated carbon. Bioprocess. Eng. 23, 295-301.

[33] Zille, A., Tzanov, T., Gübitz, G.M., Cavaco-Paulo, A. 2003. Immobilized laccase for decolourization of reactive Black 5 dyeing effluent. Biotechnol. Lett. 25, 1473-1477. 


\section{LIST OF FIGURE}

Figure 1: Overall fate of TrOCs following treatment ( $24 \mathrm{~h})$ via the tested options.

Figure 2: TrOC removal efficiencies by the EMR during operation under different mediator concentrations $(5,10$ and $20 \mu \mathrm{M})$ and TrOC concentrations (i.e., 0.5 and $0.25 \mathrm{mg} / \mathrm{L}$ corresponding to loadings of 1660 and $830 \mu \mathrm{g} / \mathrm{L} . \mathrm{d}$, respectively).

Figure 3: Enhancement of enzymatic degradation due to addition of GAC (3 g/L) and/or mediator $(5 \mu \mathrm{M})$ under different TrOC concentrations (i.e., 0.5 and $0.25 \mathrm{mg} / \mathrm{L}$ corresponding to loadings of 1660 and $830 \mu \mathrm{g} / \mathrm{L} . \mathrm{d}$, respectively). The error bars represent the standard deviation of available data points ( $\mathrm{n}=11-34$, depending on the option).

Figure 4: Ratio of TrOC concentration in membrane permeate and reactor supernatant during different runs. The error bars represent the standard deviation of available data $(n=11-34$, depending on the option).

Figure 5: Variation of transmembrane pressure (TMP) as a function of operating time showing the impact of GAC addition to EMR. 


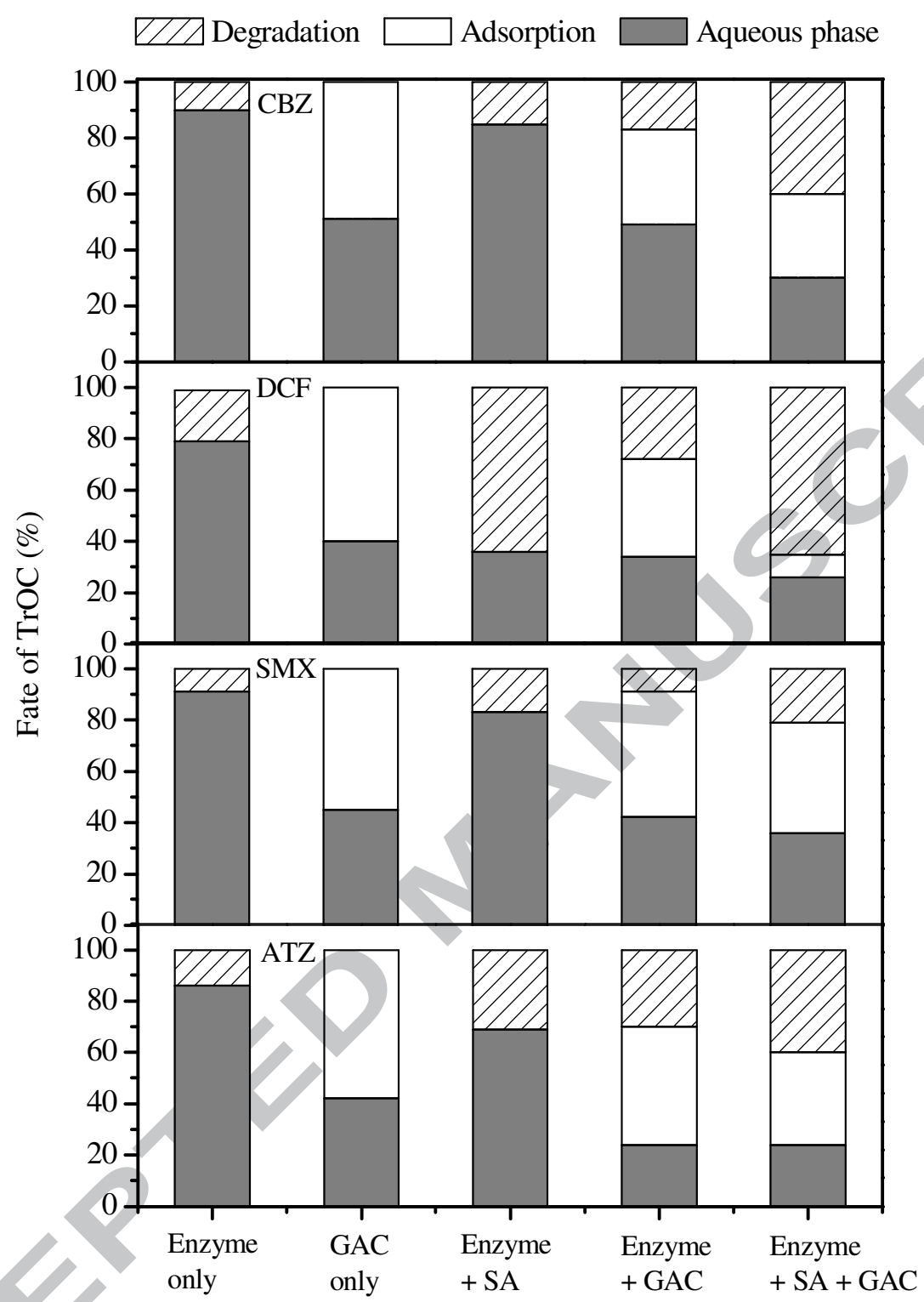

Figure 1 


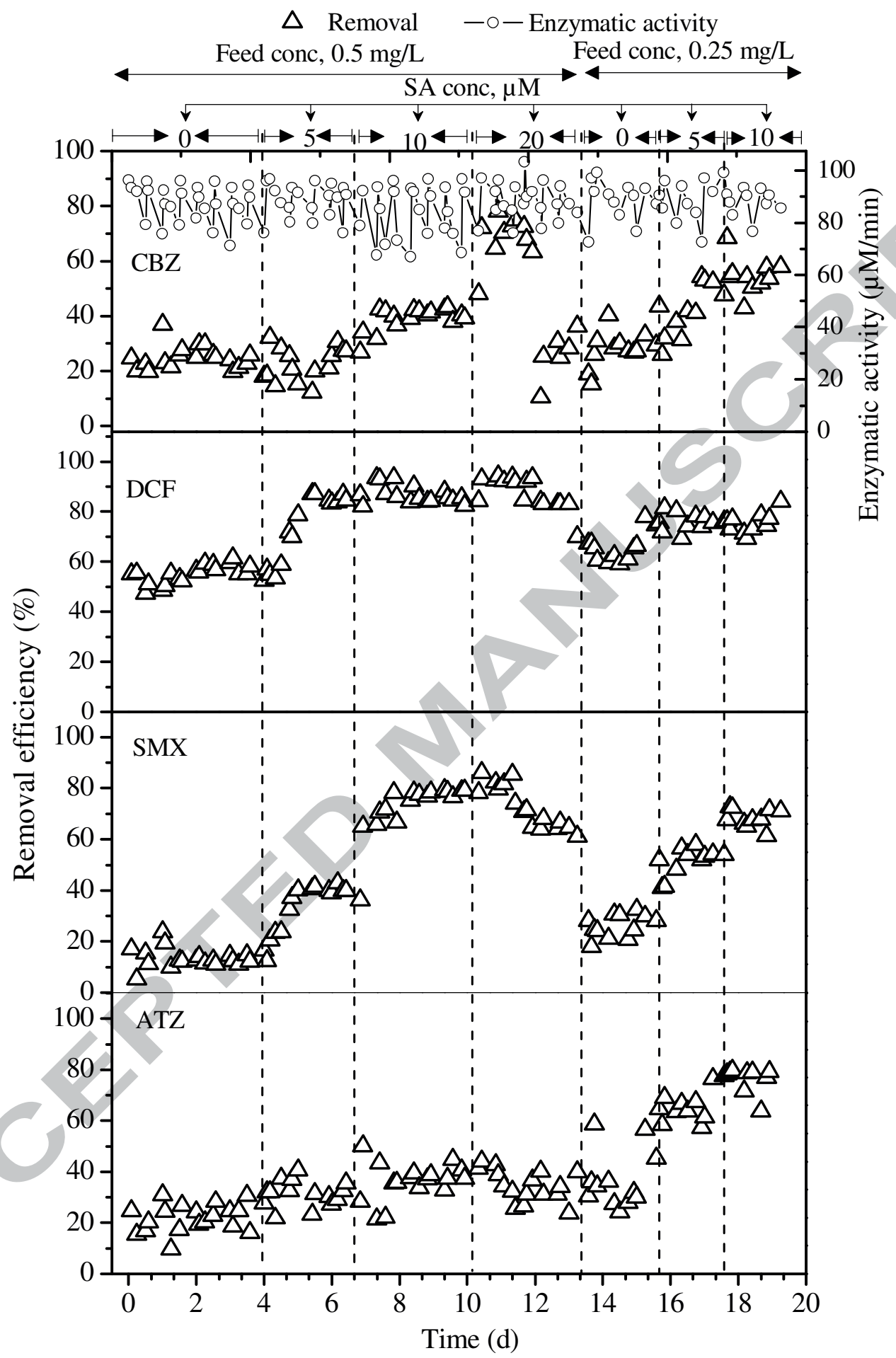

Figure 2 


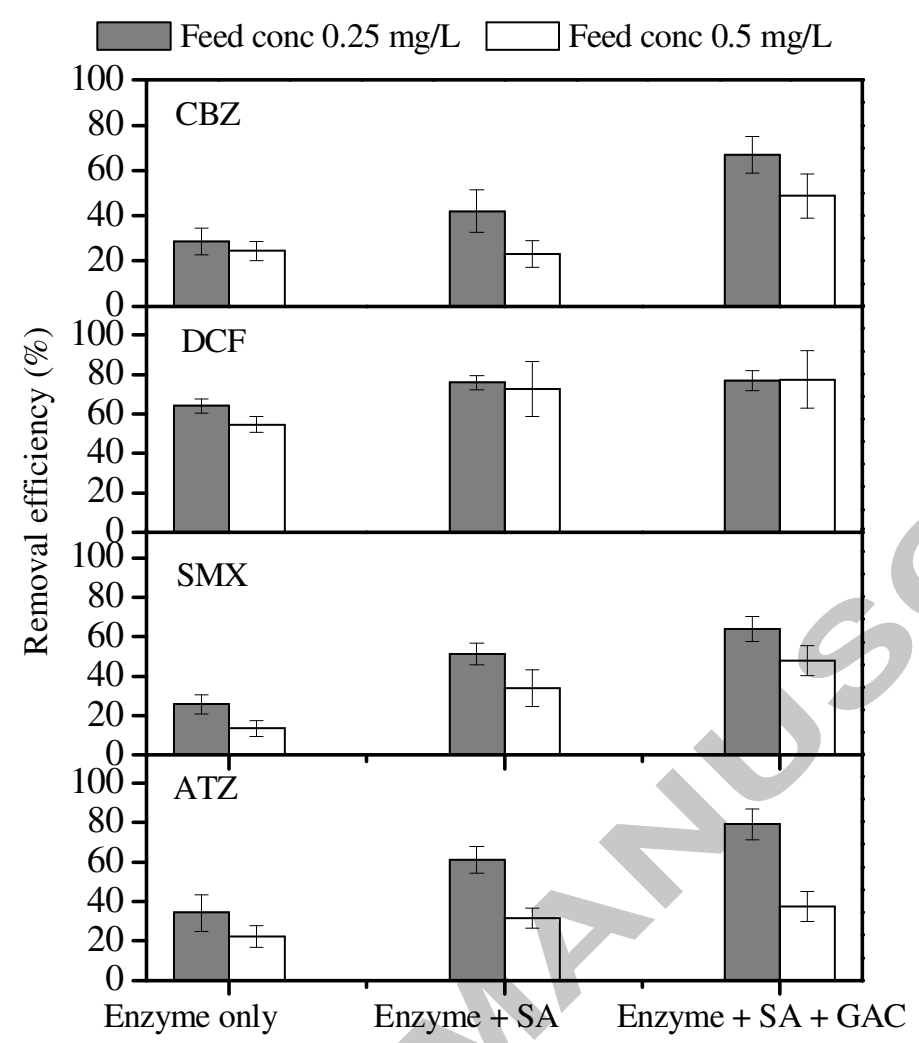

Figure 3 


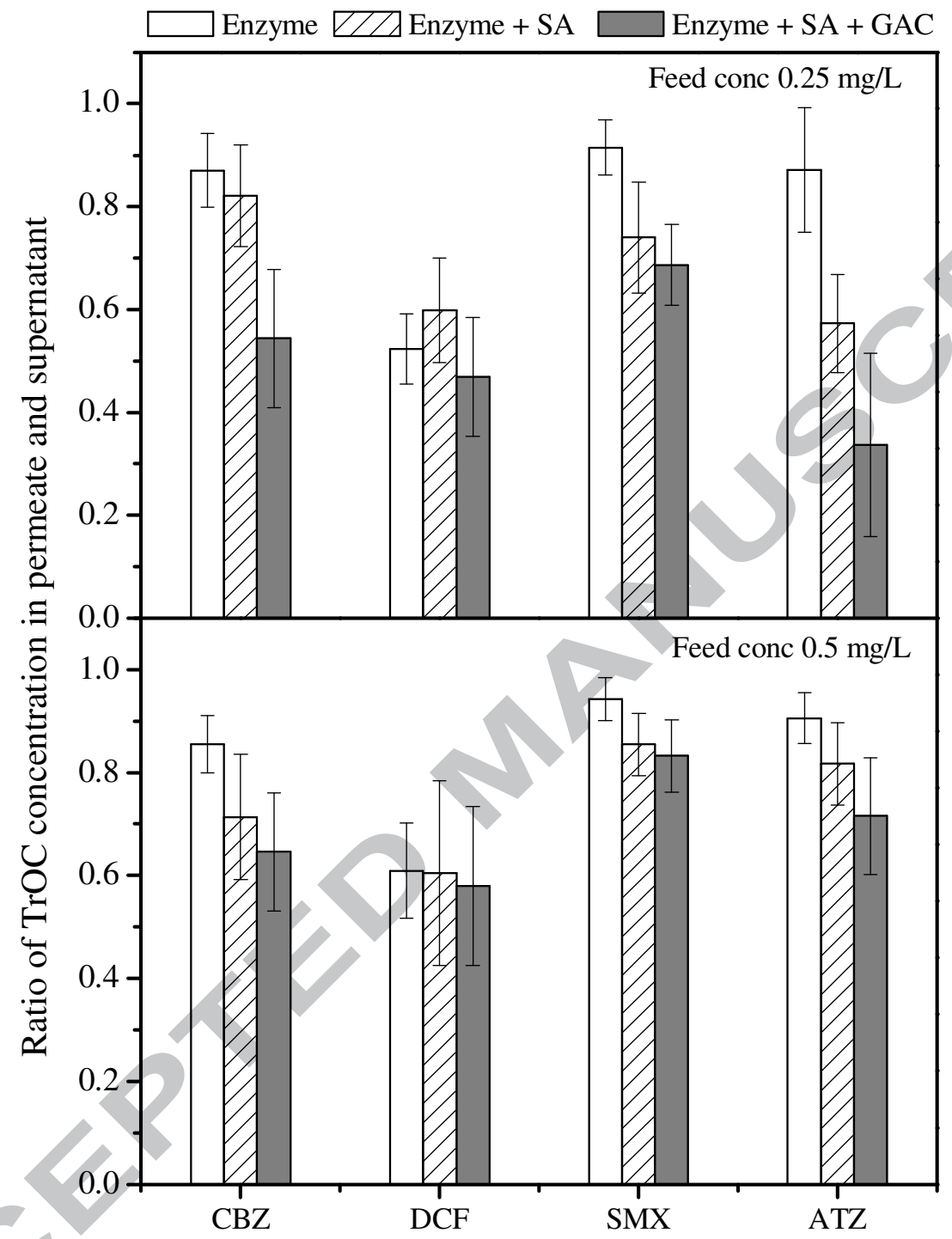

Figure 4 


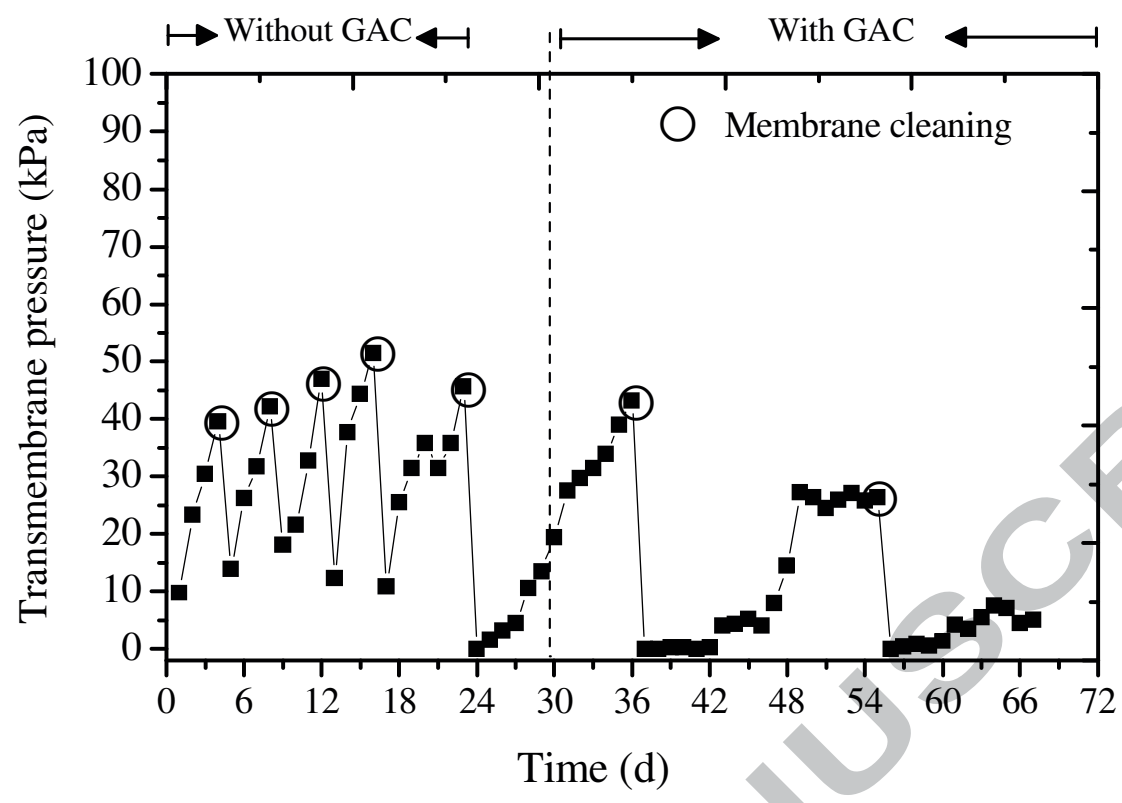

Figure 5 


\section{LIST OF TABLES}

Table 1: Aqueous phase TrOC removal efficiencies by different options in batch tests

\begin{tabular}{llllcc}
\hline \multirow{2}{*}{ Compounds } & \multicolumn{5}{c}{ Aqueous phase removal (\%) } \\
\cline { 2 - 6 } & $\begin{array}{c}\text { Enzyme } \\
\text { only }\end{array}$ & $\begin{array}{c}\text { Enzyme } \\
\text { SA }\end{array}$ & GAC only & $\begin{array}{c}\text { Enzyme }+ \\
\text { GAC }\end{array}$ & $\begin{array}{c}\text { Enzyme + } \\
\text { SA + } \\
\text { GAC }\end{array}$ \\
\hline Carbamazepine & 10 & 16 & 49 & 52 & 71 \\
\hline Diclofenac & 21 & 64 & 60 & 63 & 67 \\
\hline Sulfamethoxazole & 9 & 17 & 53 & 58 & 64 \\
\hline Atrazine & 14 & 31 & 57 & 75 & 76 \\
\hline Standard
\end{tabular}

Standard deviation of 3 replicate experiments was less than 5\%. Initial enzymatic activity was $90 \mu \mathrm{M} / \mathrm{min}$. Carbamazepine, diclofenac, sulfamethoxazole and atrazine concentrations of $5600 \pm 110,4900 \pm 160,4700 \pm 100$, and $4300 \pm 400 \mu \mathrm{g} / \mathrm{L}$, respectively were applied. SA and GAC concentrations were $10 \mu \mathrm{M}$ and $20 \mathrm{mg} / \mathrm{L}$, respectively.

Table 2: Fate of TrOCs retained within EMR

\begin{tabular}{lcccc}
\hline \multirow{2}{*}{ Compounds } & \multicolumn{3}{c}{ Total mass of TrOC $(\mathrm{mg})^{\mathrm{a}}$} & $\begin{array}{c}\text { Biodegradation } \\
(\%)^{\mathrm{b}}\end{array}$ \\
\cline { 2 - 4 } & In (I) & Out (O) & $\begin{array}{c}\text { Residual on } \\
\text { GAC (R) }\end{array}$ & 84 \\
\hline Carbamazepine & 94 & 45 & 8 & 99 \\
\hline Diclofenac & 85 & 19 & 1 & 97 \\
\hline Sulfamethoxazole & 76 & 34 & 1 & 82 \\
\hline Atrazine & 76 & 35 & 7 & \\
\hline
\end{tabular}

${ }^{a}$ At the end of the $35 \mathrm{~d}$ operation period (with GAC addition) during which the EMR was operated under different TrOC loadings and SA concentrations as detailed in Supplementary Data Table S4.

${ }^{\mathrm{b}}$ Biodegradation of the amount retained within the reactor was calculated as

Bio deg radation $(\%)=\frac{(I-O)-R}{I-O} \times 100$ 


\section{Research Highlights}

- Laccase degradation of non-phenolic persistent TrOCs was investigated by EMR

- TrOC loading greatly affected enzymatic degradation of the resistant TrOCs

- Redox-mediator notably improved TrOC degradation but increased effluent toxicity

- Simultaneous addition of a redox-mediator and GAC enhanced enzymatic degradation

- GAC addition to EMR reduced membrane fouling and toxicity of treated effluent 